DOI: https://doi.org/10.35699/2237-5864.2018.2390

\title{
EDUCAÇÃO INCLUSIVA DE ESTUDANTES SURDOS NA UNIVERSIDADE FEDERAL DE SERGIPE
}

\author{
Christianne Rocha Gomes ${ }^{1}$ \\ Joilson Pereira da Silva² \\ Rita de Cácia Santos Souza²
}

\section{RESUMO}

Diante do aumento do número de estudantes surdos no ensino superior, este artigo teórico propõe realizar uma reflexão sobre a atuação dos docentes no âmbito universitário, trazendo um breve panorama da Universidade Federal de Sergipe (UFS). Entendemos que o ensino dos surdos precisa estar em consonância com a Lei $n^{\circ} 10.436 / 2002$ e o Decreto $n^{\circ}$ 5.626/2005, reconhecendo a Língua Brasileira de Sinais (Libras) como a primeira língua dos surdos. No entanto, identificamos que a educação que tem sido ofertada nos moldes da inclusão, especificamente na UFS, não vem atendendo, na totalidade, às peculiaridades do ensino-aprendizagem do surdo. Visto que os professores desconhecem as especificidades da surdez, as metodologias estão direcionadas para a maioria que não é surda, e a formação inicial e continuada dos docentes ainda se apresenta de forma frágil. Portanto, precisamos superar essas barreiras para a aprendizagem e a participação dos surdos no ensino superior, contribuindo, assim, com a plena inclusão.

Palavras-chave: Educação inclusiva. Ensino superior. Inclusão. Surdez.

\footnotetext{
${ }^{1}$ Instituto Federal de Sergipe, Aracaju, SE, Brasil.

${ }^{2}$ Universidade Federal de Sergipe, Aracaju, SE, Brasil.
} 


\title{
INCLUSIVE EDUCATION OF DEAF STUDENTS AT THE FEDERAL UNIVERSITY OF SERGIPE
}

\author{
Christianne Rocha Gomes \\ Joilson Pereira da Silva \\ Rita de Cácia Santos Souza
}

\begin{abstract}
With the increase of deaf students in higher education, this theoretical article proposes reflection about the performance of the teaching staff in the University, bringing a brief overview of the Federal University of Sergipe (UFS). We understand that the education for deaf students must be in line with the brazilian Law No. 10.436/2002 and Decree No. 5.626/2005, recognizing Brazilian Sign Language (Libras) as the first language of the deaf. However, we have identified that the education that has been offered in the form of inclusion, specifically in the UFS, has not fully addressed the peculiarities of the teaching-learning of the deaf, since teachers are unaware of the specifics of deafness. methodologies are aimed at the non-deaf majority, and initial and continuing teacher education is still fragile. Therefore, we need to overcome these learning and participation barriers for the deaf in higher education, thus contributing to full inclusion.
\end{abstract}

Keywords: Inclusive education. Higher education. Inclusion. Deafness. 


\section{INTRODUÇÃO}

Neste artigo iremos suscitar uma reflexão com relação à atuação dos professores do ensino superior no que diz respeito ao ensino dos estudantes surdos, trazendo um breve panorama da Universidade Federal de Sergipe (UFS). De acordo com os dados do Instituto Nacional de Educação e Pesquisa Educacionais Anísio Teixeira (INEP), é crescente o número de estudantes surdos que ingressam no ensino superior no Brasil, e especificamente no estado de Sergipe, havendo um aumento significativo entre os anos de 2011 e 2015, de 24\% no Brasil e 34\% em Sergipe (INEP, 2011, 2013, 2015). Apesar desse crescimento, sabemos que esse acesso não tem sido possibilitado a todos, pois muitos indivíduos surdos ainda estão à margem dessa inclusão. Diante dessa realidade, nos questionamos: como vem sendo ofertado esse ensino? Será que os professores vêm atendendo as condições linguísticas do surdo? Vêm proporcionando a inclusão desses estudantes?

Entendemos que esse crescente aumento de alunos surdos no ensino superior deu-se em decorrência de diversos fatores, dentre os quais: o reconhecimento, a partir da Lei Federal $\mathrm{n}^{\circ}$ 10.436/2002 e do Decreto n 5.626/2005, do status de língua para a Língua de Sinais, passando esta a ser adotada como língua oficial da comunidade surda; o desenvolvimento de propostas de educação bilíngue de qualidade para surdos; e um momento histórico no qual políticas públicas de inclusão vêm aos poucos aumentando o acesso e a participação ativa de pessoas com deficiência em diferentes contextos sociais, como afirmam Bisol et al. (2010).

\section{PENSANDO A EDUCAÇÃO DOS SURDOS}

Sabemos que a inclusão dos surdos nas escolas regulares é sustentada pela legislação vigente e conta com forte e interessante arcabouço teórico-metodológico do bilinguismo, mas ainda apresenta práticas frágeis que culminam numa realidade longe de ser a ideal e a mais efetiva para o aluno surdo. Essa educação precisa estar voltada para o reconhecimento da importância da Libras, o conhecimento das peculiaridades da surdez e o respeito ao biculturalismo, isto é, a oferta da primeira língua natural, a Libras, e da segunda língua, o português escrito, possibilitando, assim, aos alunos surdos reais possibilidades para serem bilíngues, o que é respaldado nas afirmações de Mallmann et al. (2014). 
De acordo com Santos e Campos (2013), para a garantia das escolas bilíngues para surdos, além de haver o respeito à língua de sinais como primeira língua e o português como segunda, deve-se também atender às necessidades educativas específicas dos surdos, a saber: currículo adaptado, disciplina de Libras na grade curricular, professores bilíngues com fluência em Libras, intérpretes qualificados, materiais e livros didáticos adaptados, avaliação especializada em Libras para surdos. No entanto, o que vem ocorrendo na prática é que as escolas vêm apresentando uma compreensão distorcida desse bilinguismo, entendendo-o como inclusão em salas regulares, promovendo apenas o contato com ouvintes, o que possibilitaria apenas uma interação (surdo-ouvinte).

Entendemos que a inclusão de surdos na escola regular da forma como vem sendo executada em muitas instituições não é a melhor alternativa para eles, nem na perspectiva pedagógica, nem na psicológica, nem na sociocultural, nem na científica. Para Sá (2011), o ideal é que eles tenham direito de acesso à escola bilíngue específica para surdos ou à classe bilíngue específica para surdos, visto que essa é uma escola que propicia um ambiente linguístico natural favorável à aquisição da Língua de Sinais em idade precoce. Isso não significa que devemos fazer oposição ao princípio da inclusão, mas destacamos que ele não pressupõe necessariamente inclusão escolar, pois mais importante que esta é a efetiva inclusão social.

A partir de um ambiente linguístico natural para a aquisição da primeira língua, o surdo terá condições de desenvolver a consciência metalinguística, ampliando as possibilidades de aprendizagem da segunda língua. Mas esse desenvolvimento nem sempre poderá acontecer com naturalidade numa escola onde os surdos são minoria, onde a definição da surdez se dá a partir do deficit auditivo e onde a língua e a cultura dele não são priorizadas. Portanto:

\begin{abstract}
como o problema da surdez está localizado num corpo individual, ou em minorias numéricas, a perspectiva da maioria ouvinte é constantemente assegurada, ressaltando os benefícios da escola inclusiva para os ouvintes e a "necessidade" que os surdos têm de conviver com "os normais" para se "consertar", bem como a necessidade de haver surdos nas escolas regulares para incentivarem os ouvintes a aprenderem a língua de sinais e a aprenderem a conviver com as diferenças que existem na sociedade (SÁ, 2011, p. 56).
\end{abstract}

De acordo com Kotaki e Lacerda (2013), o trabalho do intérprete traz uma melhoria significativa no atendimento escolar do surdo, visto que possibilita a comunicação que é estabelecida com base no respeito com relação às condições linguística e cultural do surdo, propiciando o 
desenvolvimento desse indivíduo e a aquisição, por parte dele, de novos conhecimentos de maneira adequada. Portanto, para a efetivação do processo de educação inclusiva dos surdos, um dos aspectos essenciais é a estrutura dispor de intérpretes nas salas de aula. Embora essencial, a presença do intérprete de língua de sinais não é suficiente.

A inclusão requer uma profunda reflexão sobre as responsabilidades e o papel do professor e da instituição formadora como um todo (BISOL et al., 2010). Verificamos, muitas vezes, que, mesmo com a presença do intérprete de Libras, a inclusão não é verdadeira: os professores não fazem alterações nas aulas que ministram, os alunos ouvintes nem sempre são conscientizados das implicações da presença de um aluno surdo em sala de aula, o próprio sujeito surdo, muitas vezes, não sabe usar o serviço do intérprete, como afirma Moura (2000).

Em seguida, apresentaremos um cenário da educação inclusiva do surdo no ensino superior, abordando brevemente os desafios e possibilidades.

\section{PENSANDO A EDUCAÇÃO INCLUSIVA DOS SURDOS NO ENSINO SUPERIOR}

Apesar de as legislações vigentes versarem sobre a inclusão dos surdos nos sistemas educacionais, essa inclusão ainda não foi efetivamente implantada com as devidas qualidades, e as instituições de ensino não estão preparadas para responder adequadamente às necessidades desses alunos. Observamos que as condições linguísticas e específicas dos surdos ainda não estão sendo atendidas na totalidade, visto que a condição bilíngue dos surdos não é respeitada; por despreparo, os professores desconhecem as especificidades da Libras e não sabem como trabalhá-la didaticamente (DAROQUE; QUEIROZ, 2013).

O aluno surdo brasileiro do ensino superior, geralmente, tem formação frágil desde os ensinos fundamental e médio. $O$ fato de as instituições de ensino não atenderem às condições específicas desse aluno tem repercutido negativamente na trajetória escolar desse grupo, a qual costuma se alongar, os alunos acabam tendo uma aprendizagem insuficiente e sem alcançar o domínio da língua portuguesa na modalidade escrita, por exemplo. Dessa forma, poucos alunos surdos conseguem ingressar no ensino superior e, quando isso acontece, deparam-se com muitos obstáculos. Apesar de pequeno o número de alunos surdos nesse grau de escolaridade, tem-se observado um crescimento desse número em virtude dos movimentos de luta das comunidades surdas em busca de legitimação da língua que utilizam, de acordo com os estudos de Daroque e Queiroz (2013). 
Sabemos que o contexto universitário é desafiador para todos os jovens, e os problemas de adaptação à vida acadêmica e às obrigações que ela impõe os conduzem, muitas vezes, ao fracasso e ao abandono. No caso específico do estudante surdo, essa situação é ainda mais complexa, visto que o funcionamento da universidade é regido por normas, princípios e características do mundo ouvinte, no qual a comunicação oral-auditiva desempenha o papel central na organização dos espaços de ensino-aprendizagem e de socialização, sendo um grande desafio para eles estarem em um ambiente onde a surdez e a comunicação visual não são a regra, e a identidade surda não é considerada devidamente. Sendo assim, por fazerem parte de uma minoria, precisam se adaptar à "comunidade dos ouvintes" e enfrentar o grande desafio de transitar entre a língua de sinais e a língua portuguesa, como afirmam Bisol et al. (2010).

Outro aspecto relevante no âmbito universitário é que a leitura e a escrita são um grande desafio, não só para o estudante surdo, mas também para boa parte dos estudantes universitários que trazem deficiências de compreensão e falta de hábito e gosto pela leitura. No caso dos surdos, o baixo nível de letramento e as dificuldades na aprendizagem da leitura e da escrita, na maioria das vezes, foram decorrentes do fato de os ambientes em que eles cresceram terem sido limitados linguisticamente, o que não possibilitou o desenvolvimento das competências linguísticas necessárias para fazer uso efetivo da interpretação ou dos livros didáticos (BISOL et al., 2010).

Identificamos que no ensino superior a introdução da Libras como disciplina curricular representa muito mais que o ensino de uma língua, pois requer que todos os envolvidos nessa aprendizagem compreendam a especificidade do surdo, não apenas com relação à própria língua, mas também com relação à cultura e à forma de estar na sociedade, como ressaltam Moura e Harrison (2010). Em muitos espaços, inclusive nos espaços acadêmicos, ainda é importante pensar a diferença linguística como marca identitária para o fortalecimento político da identidade surda (LOPES, 2011). Portanto:

Ao trazerem a Língua de Sinais Brasileira para o debate acadêmico, os surdos, ao mesmo tempo que evidenciam a fragilidade de se pensar o ensino centrado apenas no ouvir e no falar, também procuram libertar-se das amarras da Língua Portuguesa em seu desenvolvimento intelectual. Para eles, a Língua de Sinais não é um instrumento de comunicação para facilitar a aprendizagem da Língua Portuguesa, mas de transformação das relações sociais, culturais e institucionais que 
geraram e geram as representações hegemônicas sobre o ser surdo no sistema de ensino (SILVA, 2006, p. 86).

Alguns estudiosos acreditam que a inclusão é um ideal e que na prática os obstáculos são concretos e se manifestam nos mínimos detalhes. O professor em sala de aula, no caso do ensino superior, escreve rapidamente no quadro ao mesmo tempo em que dá explicações. Está acostumado a uma dinâmica da comunidade acadêmica ouvinte, em que os alunos escutam e tomam notas simultaneamente. Isso obriga o estudante surdo a desenvolver estratégias para conseguir acompanhar o ritmo da aula.

É importante salientar que grande parte desses professores recebeu uma formação direcionada ao trabalho com um público homogêneo, falante da língua portuguesa e que compartilha a língua do professor. Ao se deparar com o novo, o diferente, com o aluno surdo sinalizador, que faz uso da Língua de Sinais, esse professor encontrará um grande desafio, nos advertem Bisol et al. (2010). A falta de conhecimento do professor com relação à surdez é um fator preocupante, pois pode levar aquilo que não desejamos para nenhuma universidade, isto é, "a inclusão perversa que finge que incluem para apenas cumprir o papel de dar um certificado que pouca serventia terá para um profissional despreparado" (MOURA; HARRISON, 2010, p. 353).

Estudos mostram que a inadequada formação inicial e continuada dos professores da educação básica e do ensino superior com bases inclusivas pode ser considerada como um dos grandes obstáculos para a inclusão dos alunos com deficiência, pois ainda há um grande vazio em programas ou projetos que envolvam ações relacionadas à qualificação do corpo docente em propostas mais inclusivas (MOREIRA; BOLSANELLO; SEGER, 2011).

É preciso reconhecer que a instituição de ensino superior, assim como a sociedade em geral, está pouco preparada para receber o estudante surdo. As minorias e os outros grupos marginalizados enfrentam vários obstáculos, pois é difícil alterar as definições impostas pela maioria, que, no ambiente universitário, tem pouco convívio direto com os surdos e pouco ou nada conhece sobre a surdez ou sobre a Língua de Sinais (BISOL et al., 2010). Corroborando essas afirmações, Cavallari (2010) destaca, no estudo que realiza, que a inclusão ainda não foi alcançada de fato e que a função social exercida pela universidade e seus representantes acaba sendo a de normalizar e hospedar, por vezes hostilizar, o diferente, sem de fato incluí-lo de modo significativo. 
A inclusão provoca a desestabilização de estruturas cristalizadas. Tanto os professores quanto os alunos ouvintes precisam rever o modo de organização e as interações na sala de aula e devem sempre considerar que as relações devem ser estabelecidas num contexto de diversidade. Além disso, é necessário pensar com cuidado as metodologias a serem implementadas no contexto da inclusão, para que os insucessos pedagógicos não sejam falsamente justificados por desinteresse ou desatenção por parte do estudante surdo (BISOL et al., 2010, p. 164).

Além disso, entendemos que a viabilização da inclusão no contexto escolar não depende única e exclusivamente da "boa" vontade dos educadores ou do poder transformador que eles possuem, visto que os mecanismos de exclusão, bem como o modelo de escola excludente que ainda é predominante em nosso país, foram legitimados ao longo de uma trajetória político-econômica que, por meio de práticas discursivas, foram construindo verdades sobre os excluídos e sobre a necessidade de incluí-los, enfatiza Cavallari (2010).

Em seguida, abordaremos brevemente como foi se configurando o contexto da educação inclusiva dos surdos na Universidade Federal de Sergipe.

\section{PENSANDO O CONTEXTO DA UNIVERSIDADE FEDERAL DE SERGIPE}

No caso específico da Universidade Federal de Sergipe, desde a década de 1990, havia na instituição um grupo de estudo liderado pela professora doutora lara Maria Campelo Lima, com o objetivo de dialogar sobre a educação especial na perspectiva inclusiva. Esse grupo, em parceria com o Governo do Estado, firmou um convênio com o Centro de Referência Latino-Americano para Educação Especial/Cuba-CELAEE, visando à formação de recursos humanos para atuar na área e implantar em Sergipe o Centro de Referência em Educação Especial, como afirma Cruz (2016). Naquele momento, professores estaduais, técnicos e alguns professores da UFS foram capacitados, e os cursos tiveram duração de seis meses contínuos, com locais e demandas distintas: professores e técnicos da rede estadual fizeram o curso no antigo Centro de Educação Especial João Cardoso do Nascimento Júnior, hoje Escola Especial João Cardoso do Nascimento Júnior, com foco nas práticas pedagógicas, e os técnicos da comunidade sergipana e alguns professores da UFS, no auditório do Centro de Educação e Ciências Humanas da UFS, com foco em atendimentos especializados, como em psicologia, fonoaudiologia, psicopedagogia, dentre outras, para que pudessem contribuir com o desenvolvimento da aprendizagem dos alunos usando a experiência cubana e os estudos de Vygotsky como referência. 
Cabe destacar que, segundo Cruz (2016), o Departamento de Psicologia da UFS foi o pioneiro na oferta de uma disciplina que abordava aspectos da pessoa com deficiência, denominada Psicologia do Excepcional. No momento da criação desse departamento, em 1990, os professores doutores Maria Stela de Araújo Albuquerque Bergo, José Carlos Tourinho e Gizelda Santana de Moraes elaboraram a grade curricular inserindo essa disciplina, que era ofertada nos cursos de formação de professores na UFS. No entanto, chama a nossa atenção a lacuna, de mais de duas décadas, de produções por profissionais da Psicologia dessa instituição no campo da educação inclusiva.

A partir do segundo semestre de 2007, foi constituído o Núcleo de Pesquisa em Inclusão Escolar da Pessoa com Deficiência (NUPIEPED), tendo como líder a professora doutora Verônica Reis Mariano de Souza e como vice, a partir de 2009, a professora doutora Rita de Cácia Santos Souza. Em 2009, com o intuito de fortalecer as iniciativas na área, somam-se ao NUPIEPED os profissionais que integravam o grupo de estudo da professora doutora lara Maria Campelo Lima e outros profissionais estudiosos da área, assim como os estudantes e profissionais do Núcleo de Estudo, Extensão e Pesquisa em Educação, Arte e Diversidade, liderado pela professora doutora Rita de Cácia Santos Souza, na Universidade Tiradentes. Juntos, passaram a desenvolver ações de ensino, pesquisa e extensão visando contribuir com o acesso, a permanência e a conclusão dos cursos para os alunos com deficiência, ressaltam Souza et al. (2014). Esse núcleo é um rico espaço de discussões, pesquisas e disseminação de publicações na área da educação inclusiva por estudiosos sergipanos.

O NUPIEPED contribuiu com a implantação do Programa Incluir, que está representado na UFS pelo Programa de Ações Inclusivas (PAI/UFS). Esse Programa visa melhorar as condições de acessibilidade dos estudantes com deficiência matriculados que busquem apoio para locomoção ou necessidades educativas, além de prestar serviço de orientação a estudantes sobre os direitos que possuem e a professores sobre o processo de ensino-aprendizagem do aluno com deficiência.

A Resolução no 80/2008/CONEPE também foi um importante marco para as ações inclusivas na UFS, pois institui o programa de ações afirmativas para garantia de acesso de grupos menos favorecidos e regulamenta que os cursos de graduação, ministrados pela UFS ofertarão, necessariamente, uma vaga para candidatos com deficiência comprovada por meio de relatório médico. Portanto, foi somente a partir de 2009, com a aplicação dessa resolução, que 
os processos seletivos dessa universidade passaram a garantir reserva de vagas para pessoas com deficiência.

A UFS conta com a Divisão de Ações Inclusivas (DAIN), criada em 2014, por meio da Resolução 03/2014/CONSU, que aprova alteração no Regimento Interno da Reitoria. A DAIN faz parte da Coordenação de Assistência e Integração do Estudante (CODAE), da Pró-Reitoria de Assuntos Estudantis, e é um setor responsável pela orientação e pelo apoio aos alunos com deficiência e pela coordenação das ações desenvolvidas pelo Programa Incluir e pelo Programa de Ações Inclusivas da UFS.

A DAIN tem por competência:

- $\quad$ atender alunos com deficiência;

- desenvolver campanhas sobre acessibilidade na comunicação acadêmica;

- $\quad$ orientar professores e técnicos a respeito dos direitos acadêmicos dos alunos com deficiência e das adaptações pedagógicas;

- $\quad$ promover estratégias de acessibilidade pedagógica;

- fornecer equipamentos e serviços de tecnologia assistiva para os alunos com deficiência;

- sensibilizar os diversos setores da UFS quanto às questões de acessibilidade pedagógica, de comunicação, arquitetônica e cultural³.

Diversas ações vêm sendo desenvolvidas na UFS em prol da inclusão das pessoas com deficiência, dentre elas, destacamos: em 2013, a I Semana de Ações Inclusivas para realização de debates na área de acessibilidade; em 2015, o Dia Nacional da Libras e a II Semana de Ações Inclusivas e o V Encontro de Pesquisa em Inclusão Escolar da Pessoa com Deficiência, em parceria com o NUPIEPED; em 2016, o I Congresso Nacional de Libras no Campus São Cristóvão; dentre outras.

Cruz (2016) adverte que, no quesito educação inclusiva dos surdos, o ano de 2014 foi marcante para a comunidade surda, pois foi o momento em que o curso de Licenciatura em Letras-Libras

${ }^{3}$ PORTAL da Divisão de Ações Inclusivas (DAIN) da UFS. Disponível em: <http://proest.ufs.br/pagina/20079-divisao-de-acoes-inclusivas-dain>. Acesso em: 14 maio 2018. 
foi implantado na UFS, tornando-se uma realidade dos pontos de vista legal, acadêmico, social e linguístico. O projeto inicial do curso teve como mentoras quatro professoras: mestra Larissa Silva Rebouças, mestra Margarida Maria Teles, doutora Raquel Meister Ko Freitag e doutora Rita de Cácia Santos Souza. Inicialmente o Departamento de Letras se recusou a implantar esse curso, mas, após reordenamento financeiro, aceitou, reestruturou a proposta e implementou um projeto com a perspectiva de atender apenas aos ensinos fundamental maior e médio. A proposta inicial contemplava a educação do surdo desde a educação infantil.

Ressaltamos que, desde a publicação do Decreto $n^{\circ} 5.626 / 2005$, já se falava da implantação dos cursos de Letras-Libras nas Instituições de Ensino Superior (IES) e da formação de profissionais nessa área. Reconhecemos que esse curso possibilita a inclusão dos surdos no ensino superior brasileiro com qualidade, direito nunca usufruído antes por essa minoria social, e, consequentemente, possibilita a inclusão desse grupo no mercado de trabalho.

Em um levantamento realizado pela DAIN, em julho de 2016, no que se refere ao quantitativo de pessoas matriculadas na UFS e que declaram apresentar alguma necessidade específica, foram apresentados os seguintes dados (TABELA 1):

Tabela 1 - Alunos da UFS em situação de deficiência com matrículas ativas em 2016.1

\begin{tabular}{ccc}
\hline $\mathbf{N}^{\circ}$ & SITUAÇÃO DE DEFICIÊNCIA & QUANTITATIVO DE ALUNOS \\
\hline 1. & Deficiência auditiva & 17 \\
2. & Autismo & 2 \\
3. & Baixa visão & 47 \\
4. & Cegueira & 13 \\
5. & Deficiência física & 111 \\
6. & Deficiência intelectual & 3 \\
7. & Surdez & 32 \\
\hline
\end{tabular}

Fonte: Divisão de Ações Inclusivas - DAIN da UFS (2016).

Diante do panorama apresentado na Tabela 1, compreendemos a surdez como a terceira maior necessidade específica que contempla estudantes regularmente matriculados na UFS, distribuídos em diversos cursos, sendo a concentração maior no curso de Letras-Libras, como podemos constatar na Tabela 2. Destacamos que, em nível de doutorado, no momento, a instituição tem uma aluna surda cursando, o que representa uma ascensão na formação profissional de membros da comunidade surda. 
Tabela 2 - Quantitativo de surdos por cursos na UFS

\begin{tabular}{clc}
\hline No & \multicolumn{1}{c}{ CURSOS } & QUANTIDADE DE ALUNOS SURDOS \\
\hline 1. & Design Gráfico & 1 \\
2. & Odontologia & 1 \\
3. & Educação Física & 2 \\
4. & Teatro & 2 \\
5. & Pedagogia & 1 \\
6. & Engenharia de Computação & 1 \\
7. & Ciência da Computação & 1 \\
8. & Biblioteconomia & 1 \\
9. & Engenharia Florestal & 1 \\
10. & Letras-Libras & 20 \\
11. & Doutorado & 1 \\
\hline
\end{tabular}

Fonte: Divisão de Ações Inclusivas - DAIN da UFS (2016).

Percebemos que, para a execução da proposta de inclusão, é necessário, tanto no ensino superior quanto no básico, que se tenha uma organização pedagógica planejada, devidamente financiada para assegurar os apoios e recursos físicos, humanos e materiais aos alunos com deficiência. Além disso, é primordial que a universidade aprimore principalmente a acessibilidade física, pois esta incide diretamente na inclusão educacional e social dos alunos, sendo preciso investir e oferecer igualdade de condições para acesso e permanência de todos os alunos. E que as barreiras arquitetônicas sejam visualizadas não apenas como um conjunto de rampas e medidas a serem respeitadas, mas como uma filosofia geral de acolhimento, conforto e facilidades em todas as dependências dos edifícios (MOREIRA; BOLSANELLO; SEGER, 2011).

\section{CONSIDERAÇÕES FINAIS}

Reconhecemos que a inclusão de pessoas com deficiência no ensino superior é recente, e a real inclusão está muito longe de ser alcançada, sendo necessário o esforço de todos os envolvidos nesse processo. Compreendemos, como condição salutar, a formação inicial e continuada de toda a comunidade acadêmica com relação à educação inclusiva dos surdos. 
Entendemos que cabem às instituições de ensino superior, que têm grande responsabilidade perante a sociedade quanto à qualificação dos cidadãos e ao avanço do conhecimento, repensar as estratégias que adotam e investir em pesquisas que contribuam para um maior entendimento dos desafios e para a criação de contextos que favoreçam os processos inclusivos.

Diante do que foi apresentado, entendemos que incluir não é nivelar nem uniformizar o discurso e a prática, mas, sim, valorizar e respeitar as diferenças. A escola deve abrigar as diferenças na diversidade, respeitando a pluralidade daqueles que sempre foram vitimados por um sistema de ensino pautado na educação de poucos, dotados de privilégios econômicos, sociais, culturais, etc. O objetivo da educação inclusiva é conseguir uma educação de qualidade para todos, em conformidade com a diversidade existente entre os alunos. Incluir é considerar a diversidade não só como fator inerente à pessoa, mas também como fator enriquecedor e positivo, tanto no plano acadêmico como no pessoal. É buscar a eliminação de qualquer barreira social e educativa de caráter exclusivista que impeça o exercício de uma educação de qualidade para todos. Um dos desafios é avançar no conhecimento de novas formas de entender a educação e nas propostas para o seu desenvolvimento, desafio que pode encontrar resposta na educação inclusiva.

Devemos estar atentos também para a política de inclusão não acabar praticando uma "inclusão selvagem", isto é, impondo a matrícula e a permanência de todos os alunos na escola regular, desconsiderando as necessidades especiais de recursos, suportes e serviços especializados para significativos segmentos da população escolar, pois, dessa forma, a política de inclusão estará forjando a garantia de igualdade das condições para a escolarização.

Diante do exposto, é possível perceber que a trajetória da inclusão do surdo no ensino superior é desafiante e que a Universidade Federal de Sergipe vem procurando dar a sua contribuição para o acesso e a permanência desse aluno, mas os desafios ainda são inúmeros.

Constatamos também que inúmeros profissionais e estudantes pesquisadores têm se somado na busca de estratégias, produções científicas e ações de extensão para fazer com que a educação do surdo no ensino superior deixe de ser, cada vez mais, uma utopia e torne-se uma educação de qualidade que dá também condições de acesso digno ao trabalho. 


\section{REFERÊNCIAS}

BRASIL. Lei $n^{\circ}$ 10.436, de 24 de abril de 2002. Dispõe sobre a Língua Brasileira de Sinais - Libras e dá outras providências. Diário Oficial [da] República Federativa do Brasil, Poder Executivo, Brasília, DF, 25 abr. 2002. Disponível em: <http://www.planalto.gov.br/ ccivil_03/leis/2002/I10436.htm>. Acesso em: 6 ago. 2014.

BRASIL. Decreto $n^{\circ} 5.626$, de 22 de dezembro de 2005. Regulamenta a Lei $n^{\circ} 10.436$, de 24 de abril de 2002, que dispõe sobre a Língua Brasileira de Sinais - Libras, e o art. 18 da Lei $n^{\circ} 10.098$, de 19 de dezembro de 2000. Diário Oficial [da] República Federativa do Brasil, Poder Executivo, Brasília, DF, 13 dez. 2005. Disponível em: <http://www.planalto. gov.br/ccivil_03/_ato2004-2006/2005/decreto/d5626.htm>. Acesso em: 6 ago. 2014.

BISOL, Cláudia A. et al. Estudantes surdos no ensino superior: reflexões sobre a inclusão. Cadernos de Pesquisa, São Paulo, v. 40, n. 139, p. 147-172, jan./abr. 2010. Disponível em: <http://www.scielo.br/pdf/cp/v40n139/v40n139a08.pdf>. Acesso em: 5 nov. 2014.

CAVALLARI, Juliana S. O equívoco no discurso da inclusão: o funcionamento do conceito de diferença no depoimento de agentes educacionais. Revista Brasileira de Linguística Aplicada, v. 10, n. 3, p. 667-680, 2010. Disponível em: <http://www.scielo.br/pdf/rbla/ v10n3/a09v10n3>. Acesso em: 10 nov. 2014.

CRUZ, Cândida L. P. Tessituras da inclusão na Universidade Federal de Sergipe: múltiplos olhares. 2016. 163 f. Dissertação (Mestrado em Educação) - Universidade Federal de Sergipe, São Cristóvão, SE, 2016.

DAROQUE, Samantha C.; QUEIROZ, Guilherme A. Inclusão de surdos no ensino superior. O que tem de bilíngue? In: ALBRES, Neiva A.; NEVES, Sylvia. L. G. (Org.). Libras em estudo: política educacional. p. 139-163. 2013. Disponível em: <http://www.feneissp.org.br/ index.php/e-books>. Acesso em: 3 dez. 2014.

INSTITUTO NACIONAL DE ESTUDOS E PESQUISAS EDUCACIONAIS ANÍSIO TEIXEIRA - INEP. Sinopse estatística da educação superior 2011, 2013 e 2015. Disponível em: <http:// portal.inep.gov.br/sinopses-estatisticas-da-educacao-superior>. Acesso em: 7 fev. 2016.

KOTAKI, Cristiane S.; LACERDA, Cristina. B. F. de. O intérprete de Libras no contexto da escola inclusiva: focalizando sua atuação na segunda etapa do ensino fundamental. In: LACERDA, Cristina B. F. de; SANTOS, Lara F. dos (Org.). Tenho um aluno surdo, e agora? Introdução à Libras e educação de surdos. São Carlos: EdUFSCar, 2013. p. 201-218.

LOPES, Maura C. Surdez e educação. 2. ed. Belo Horizonte: Autêntica, 2011. 
MALLMANN, Fagner M. et al. A inclusão do aluno surdo no ensino médio e ensino profissionalizante: um olhar para os discursos dos educadores. Revista Brasileira Educação Especial, Rio de Janeiro, v. 20, n. 1, p. 131-146, jan./mar. 2014. Disponível em <http://dx.doi.org/10.1590/S1413-65382014000100010>. Acesso em: 10 mar. 2015.

MOREIRA, Laura C.; BOLSANELLO, Maria A.; SEGER, Rosangela G. Ingresso e permanência na Universidade: alunos com deficiência em foco. Educar em Revista, v. 41, p. 125-143, jun./ set. 2011. Disponível em: <http://revistas.ufpr.br/educar/article/view/25006/16754>. Acesso em: 22 out. 2014.

MOURA, Maria. C. O surdo: caminhos para uma nova identidade. Rio de Janeiro: Revinter, 2000.

MOURA, Maria C. de; HARRISON, K. M. P. A inclusão do surdo na universidade - Mito ou realidade?. Cadernos de Tradução, Santa Catarina, v. 2, n. 26, p. 333-358, 2010. Disponível em: <http://dx.doi.org/10.5007/2175-7968.2010v2n26p333>. Acesso em: 22 mar. 2015.

UNIVERSIDADE FEDERAL DE SERGIPE. Resolução n 80/2008/CONEPE. Institui o programa de ações afirmativas para garantia de acesso de grupos menos favorecidos à Universidade Federal de Sergipe. Disponível em: <www2.ccv.ufs.br/ccv/concursos/pss2010/files/ manual/res_conepe802008.pdf>. Acesso em: 25 fev. 2015.

UNIVERSIDADE FEDERAL DE SERGIPE. Resolução n 3/2014/CONSU. Aprova alterações do Regimento interno na Reitoria da UFS. Disponível em: <cinttec.ufs.br/uploads/.../ Resolu_o_N_03_14_-_Regimento_interno_da_Reitoria.pdf.>. Acesso em: 25 fev. 2015.

SÁ, Nidia L. Escolas e classes de surdos: opção político-pedagógica legível. In: SÁ, Nidia L. (Org.). Surdos: qual a escola?. Manaus, AM: Valer e Edua, 2011. p.17-62.

SANTOS, Laura F. dos; CAMPOS, Maria de L. I. L. Educação especial e educação bilíngue para surdos: as contradições da inclusão. In: ALBRES, Neiva de A.; NEVES, Sylvia L. G. (Org.). Libras em estudo: política educacional. São Paulo: FENEIS, 2013. p. 13-38. Disponível em: <http://www.feneissp.org.br/index.php/e-books>. Acesso em: 18 nov. 2014.

SILVA, Vilmar. Educação de surdos: uma releitura da primeira escola pública para surdos em Paris e do Congresso de Milão em 1880. In: QUADROS, Ronice M. (Org.). Estudos surdos I. Petrópolis, RJ: Arara Azul, 2006. p. 14-37.

SOUZA, Rita de C. S. et al. Introdução aos estudos sobre educação dos surdos. Aracaju: Criação, 2014. 


\section{Christianne Rocha Gomes}

Mestrado em Psicologia Social pela Universidade Federal de Sergipe - UFS (2017). Possui graduação em Psicologia pela UFS (2006) e especialização em Psicologia Conjugal e Familiar pela Faculdade de Sergipe (2009), assim como em Psicologia de Trânsito pela Faculdade Pio Décimo (2011). Atualmente é técnica administrativa na área de Psicologia do Instituto Federal de Sergipe.

christiannerg@hotmail.com

\section{Joilson Pereira da Silva}

Doutorado em Psicologia pela Universidade Complutense de Madri-Espanha, mestrado em Psicologia pela Universidade Federal da Paraíba, graduação em Psicologia (UFPB), graduado em Estudos Sociais e Geografia (UEPB). Atualmente é professor associado da Universidade Federal de Sergipe e professor credenciado do Programa de Pós-Graduação em Psicologia. joilsonp@hotmail.com

\section{Rita de Cácia Santos Souza}

Pós-doutorado (2014) e doutorado em Educação pela Universidade Federal da Bahia (2009), mestrado em Educação pela Universidade Federal de Sergipe - UFS (2000) e licenciatura em Pedagogia pela UFS (1993). Pesquisadora do Núcleo de Pesquisa em Inclusão Escolar da Pessoa com Deficiência - NUPIEPED (UFS), líder do Núcleo de Estudo, Extensão e Pesquisa em Inclusão e Tecnologia Assistiva (NUPITA/UFS).

ritacssouzaa@yahoo.com.br 